\title{
Increases in GABA concentrations during cerebral ischaemia: a microdialysis study of extracellular amino acids
}

\author{
P J Hutchinson, M T O'Connell, P G Al-Rawi, C R Kett-White, A K Gupta, L B Maskell, \\ J D Pickard, P J Kirkpatrick
}

J Neurol Neurosurg Psychiatry 2002;72:99-105

See end of article for authors' affiliations .....................

Correspondence to: Mr PJ Hutchinson,

Academic Department of

Neurosurgery, University of

Cambridge, Box 167

Addenbrooke's Hospital

Cambridge CB2 2QQ, UK;

p.hutch@which.net

Received

1 December 2000

In revised form 17 July

2001

Accepted 20 July 2001

\begin{abstract}
Objectives: Increases in the extracellular concentration of the excitatory amino acids glutamate and aspartate during cerebral ischaemia in patients are well recognised. Less emphasis has been placed on the concentrations of the inhibitory amino acid neurotransmitters, notably $\gamma$-amino-butyric acid (GABA), despite evidence from animal studies that GABA may act as a neuroprotectant in models of ischaemia. The objective of this study was to investigate the concentrations of various excitatory, inhibitory and non-transmitter amino acids under basal conditions and during periods of cerebral ischaemia in patients with head injury or a subarachnoid haemorrhage.

Methods: Cerebral microdialysis was established in 12 patients with head injury $(n=7)$ or subarachnoid haemorrhage $(n=5)$. Analysis was performed using high performance liquid chromatography for a total of 19 (excitatory, inhibitory and non-transmitter) amino acids. Patients were monitored in neurointensive care or during aneurysm clipping.

Results: During stable periods of monitoring the concentrations of amino acids were relatively constant enabling basal values to be established. In six patients, cerebral ischaemia was associated with increases (up to $1350 \mathrm{fold}$ ) in the concentration of GABA, in addition to the glutamate and aspartate. Parallel increases in the concentration of glutamate and GABA were found $(r=0.71, p<0.005)$.

Conclusions: The results suggest that, in the human brain, acute cerebral ischaemia is not accompanied by an imbalance between excitatory and inhibitory amino acids, but by an increase in all neurotransmitter amino acids. These findings concur with the animal models of ischaemia and raise the possibility of an endogenous GABA mediated neuroprotective mechanism in humans.
\end{abstract}

$\mathrm{T}$ -he excitatory amino acids glutamate and aspartate are thought to play an important part in the pathogenesis of neuronal damage and death in acute cerebral ischaemia. ${ }^{1-9}$ In association with reduced oxygen and substrate (glucose) delivery and increased production of protons and lactate, excessive accumulation of these amino acids results in potential pathological activation of receptors and increased calcium entry into cells. Cytoplasm swelling, mitochondrial dysfunction, and membrane disintegration occur, culminating in cell death. These processes were initially demonstrated in animal models and are currently undergoing investigation in humans. Microdialysis is currently being applied to monitor the extracellular chemistry of the brain of neurosurgical patients. ${ }^{10-17}$ Studies in patients with head injury and subarachnoid haemorrhage have disclosed increases of the extracellular concentrations of excitatory amino acids in response to secondary ischaemic events such as intracranial hypertension, systemic hypotension, seizures, and contusions. ${ }^{11-13} 16$ 18-20

By contrast, less attention has been applied to the inhibitory amino acids, notably $\gamma$-aminobutyric acid (GABA), despite experimental studies of cerebral ischaemia showing that glutamate and aspartate rises may be accompanied by changes in the concentration of other amino acids ${ }^{21-36}$ and increases in GABA concentrations in the CSF of patients with head injury. ${ }^{37}$ Although GABA was measured in the first reported human brain microdialysis study performed during thalamotomy $^{38}$ and changes in GABA concentrations have been shown during seizures, ${ }^{1639}$ after trauma, ${ }^{40}$ and in lobectomy models of ischaemia, ${ }^{41}{ }^{42}$ clinical microdialysis studies have concentrated on the excitatory amino acids.
The objective of this study was to apply microdialysis to measure the extracellular concentrations of inhibitory, excitatory, and non-transmitter amino acids in patients at risk of cerebral ischaemia after head injury and subarachnoid haemorrhage. We aimed to establish normal values of amino acids under basal conditions and changes in concentrations during episodes of cerebral ischaemia.

\section{METHODS \\ Patient selection}

The study was approved by the local research ethics committee and consent was obtained from the patient or next of kin. Patients with severe head injury and subarachnoid haemorrhage were eligible. Patients with severe head injury were monitored on the neurointensive care unit. Those with aneurysmal subarachnoid haemorrhage were monitored during aneurysm clipping in the operating theatre, and were preselected on the basis of anticipated difficulty in surgery (for example, giant aneurysms requiring temporary clipping or induced hypotension).

\section{Microdialysis technique}

The microdialysis catheter (CMA 70, CMA microdialysis, Stockholm, Sweden) was inserted into the cerebral cortex in conjunction with an intracranial pressure transducer (Codman, Raynham, MA, USA) and Neurotrend (Codman,

Abbreviations: GABA, $\gamma$-amino-butyric acid; HPLC, high performance liquid chromatography; CPP, cerebral perfusion pressure; ICP, intracranial pressure 


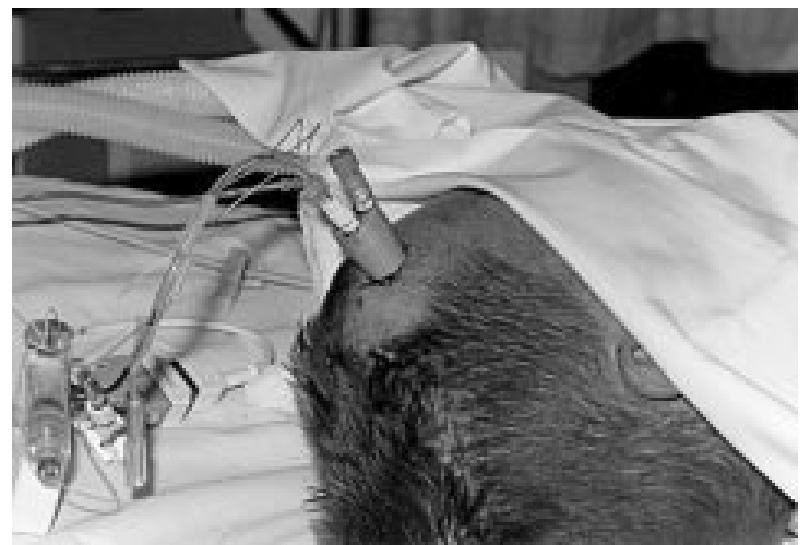

Figure 1 Triple lumen cranial access device transmitting the intracranial pressure transducer, microdialysis catheter and Neurotrend sensor into the cerebral parenchyma (with permission).

Raynham, MA, USA) multiparameter sensor via a specially designed cranial access device (triple bolt; Technicam, Newton Abbot, UK, fig 1) as described previously. ${ }^{43}$ Microdialysis was performed using Ringer's solution $\left(\mathrm{K}^{+} 4 \mathrm{mM}, \mathrm{Na}^{+} 147 \mathrm{mM}\right.$, $\mathrm{Ca}^{2+} 2 \mathrm{mM}, \mathrm{Cl}^{-} 155 \mathrm{mM}$ ) in the operating theatre (flow rate 1.0 $\mu \mathrm{l} / \mathrm{min}$, collection time 10 minutes) and neurointensive care unit (flow rate $0.3 \mu \mathrm{l} / \mathrm{min}$, collection time 30-60 minutes). Vials were analysed on line using the CMA600 microdialysis analyser and then stored at $-70^{\circ} \mathrm{C}$. Selected vials collected both under basal quiescent conditions and during periods of cerebral ischaemia (defined by intracranial hypertension, systemic hypotension, hypoxia) were then analysed for amino acids using high performance liquid chromatography (HPLC).

\section{High performance liquid chromatography analysis}

A $1 \mu \mathrm{l}$ sample was diluted (1:20) and $5 \mu \mathrm{l}$ then mixed with $3 \mu \mathrm{l}$ buffer containing norvaline (internal standard) and $3 \mu \mathrm{l}$ orthophthaldialdehyde /3-mercaptopropionic acid. The HPLC system consisted of two high pressure pumps with a gradient controller and mixing chamber (Micro-Tech Scientific, Sunnyvale, CA, USA). The amino acids were separated using a C18 column and detected using a Gilson model 122 fluorometer (Gilson, Middleton, WI, USA) fitted with a $100 \mathrm{nl}$ fluorobooster flow cell.

\section{Analysis of results}

The results were analysed by calculating the mean value of amino acid concentrations under basal conditions and changes as a result of ischaemic insults expressed as ratios (ischaemia value/baseline value). Comparison between glutamate and GABA microdialysate concentrations was made using Spearman's correlation analysis.

\section{RESULTS}

\section{Patient population}

Samples from 12 patients (seven male and five female) were analysed for extracellular amino acids using the HPLC system. Seven patients with severe head injury were monitored on the neurointensive care unit and five patients with subarachnoid haemorrhage were monitored during surgery for clipping of an aneurysm (three of whom had a temporary clip as part of the procedure).

\section{Case illustrations}

\section{Illustrative case history 1}

An 18 year old man with severe head injury (Glasgow coma $\operatorname{score}^{44}$ 3) had a secondary insult with intracranial hypertension and CT showing cerebral swelling and low attenuation areas indicative of cerebral ischaemia. Despite maximum
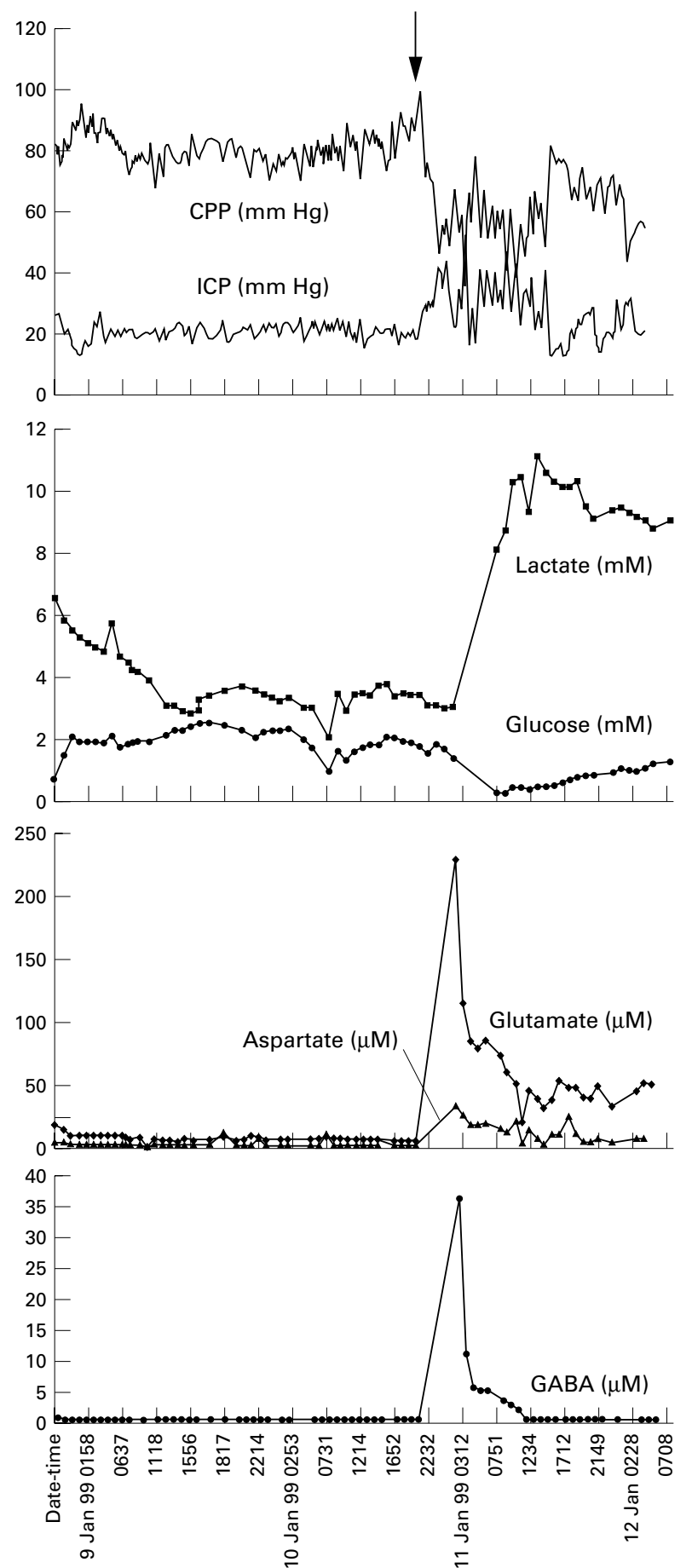

Figure 2 Severe head injury: illustrative case history 1 demonstrating secondary insult (arrow) with increase in intracranial pressure (ICP) and decrease in cerebral perfusion pressure (CPP) showing decrease in extracellular glucose, increase in lactate and increase in the excitatory amino acids glutamate and aspartate. Note that GABA was undetectable until the insult, then increased concomitantly with glutamate and then decreased to undetectable concentrations. The glutamate and aspartate concentrations did not return to the preinsult baseline but remained increased.

treatment the patient succumbed. Microdialysis showed profound disturbances in metabolism ( fig 2) with low glucose and increased lactate concentrations. The amino acid changes are shown in table 1 with increases in glutamate, aspartate, glycine, GABA, methionine and arginine. The concentration of glutamine decreased and there were less pronounced changes in the other amino acids. 
Table 1 Microdialysis amino acid analysis in a patient with severe head injury (illustrative case history 1) showing baseline values, values during ischaemic insult, and ratio (ischaemia value/baseline value) (CMA70 microdialysis catheter $10 \mathrm{~mm}$ membrane perfused with Ringer's solution at $0.3 \mu \mathrm{l} / \mathrm{min}$ ). Valine and histidine were not available in this patient. Controversy surrounds the inhibitory role of glycine and taurine

\begin{tabular}{|c|c|c|c|c|c|}
\hline Amino acid type & $\begin{array}{l}\text { Amino acid } \\
\text { name }\end{array}$ & $\begin{array}{l}\text { Base line } \\
\text { value }(\mu \mathrm{M})\end{array}$ & $\begin{array}{l}\text { Ischaemia } \\
\text { value }(\mu \mathrm{M})\end{array}$ & $\begin{array}{l}\text { Post- ischaemia } \\
\text { value }(\mu \mathrm{M})\end{array}$ & $\begin{array}{l}\text { Ratio (ischaemia } \\
\text { value/baseline } \\
\text { value) }>1 \text { increase } \\
<1 \text { decrease }\end{array}$ \\
\hline \multirow[t]{2}{*}{ Excitatory } & Glutamate & 6.77 & 228.1 & 42.8 & 33.7 \\
\hline & Aspartate & 2.32 & 32.6 & 10.8 & 14.1 \\
\hline \multirow[t]{3}{*}{ Inhibitory } & GABA & 0.06 & 35.7 & 0.08 & 595 \\
\hline & Glycine & 16.3 & 56.0 & 40.8 & 3.4 \\
\hline & Taurine & 8.6 & 18.7 & 13.0 & 2.2 \\
\hline \multirow[t]{11}{*}{ Non-transmitter } & Alanine & 10.0 & 18.7 & 13.0 & 1.9 \\
\hline & Arginine & 34.6 & 184.5 & 135.9 & 5.3 \\
\hline & Asparagine & 5.20 & 15 & 11.9 & 2.9 \\
\hline & Citrulline & 1.59 & 6.9 & 4.67 & 4.3 \\
\hline & Glutamine & 1738 & 931.5 & 1264 & 0.5 \\
\hline & Methionine & 36.8 & 191.1 & 59.9 & 5.2 \\
\hline & Phenylalanine & 22.8 & 78.5 & 45.6 & 3.4 \\
\hline & Serine & 36.1 & 86.4 & 43.4 & 2.4 \\
\hline & Threonine & 24.0 & 99.3 & 87.5 & 4.1 \\
\hline & Tryptophan & 0.69 & 2 & 0.97 & 2.9 \\
\hline & Tyrosine & 12.3 & 40.3 & 33.1 & 3.3 \\
\hline
\end{tabular}

\section{Illustrative case history 2}

A 25 year old man with severe head injury (Glasgow coma score 7) was monitored with a microdialysis catheter placed in the region of a contusion (fig 3). The patient survived with a left hemiparesis (Glasgow outcome score ${ }^{45}$ category severe disability). Microdialysis (fig 3 ) showed extremely low glucose concentrations (mean $0.01 \mathrm{mM}$ ), increased lactate concentrations (mean $5.73 \mathrm{mM}$ ) and increased glutamate (mean 62.9 $\mu \mathrm{M}$, range $17.8-230 \mu \mathrm{M}$ ) and aspartate (mean $20.4 \mu \mathrm{M}$, range 10-112 $\mu \mathrm{M})$ concentrations. There were also increased concentrations of GABA (mean $0.23 \mu \mathrm{M}$, range $<0.002-1.0$ $\mu \mathrm{M}$ ), glycine (mean $161 \mu \mathrm{M}$, range 35.6-513 $\mu \mathrm{M}$ ) and taurine (mean $29.3 \mu \mathrm{M}$, range 3.6-150 $\mu \mathrm{M}$ ). Other amino acids were essentially unchanged.

\section{Illustrative case history 3}

A 41 year old woman presented with World Federation of Neurological Societies ${ }^{46}$ grade II subarachnoid haemorrhage due to rupture of a basilar artery aneurysm. During clipping of this aneurysm a combination of hypotension and hydrocephalus resulted in cerebral ischaemia with parenchymal brain oxygen levels of $2 \mathrm{~mm} \mathrm{Hg}$. Microdialysis detected a reduction in brain glucose from $0.78 \mathrm{mM}$ to $0 \mathrm{mM}$ and increase in brain lactate from $0.97 \mathrm{mM}$ to $3.5 \mathrm{mM}$ associated with changes in amino acid concentration (table 2, fig 4). There was a large rise in glutamate and aspartate accompanied by a substantial rise in the concentration of GABA. Changes in concentration of the non-transmitter amino acids varied from no changes to a twofold increase. These changes in amino acid concentrations returned to the baseline after insertion of an external ventricular drain and the patient made a full recovery (Glasgow outcome score category good recovery).

\section{Summary of results}

For the patients with head injury, the mean values under basal conditions and values during ischaemia of the major excitatory and inhibitory amino acids (with non-transmitter amino acids for comparison) monitored with a $10 \mathrm{~mm}$ membrane microdialysis catheter at $0.3 \mu \mathrm{l} / \mathrm{min}$ on the neurointensive care unit are shown in table 3 . The concentration of glutamine was considerably higher than that of the other amino acids, and the concentration of GABA considerably lower. For the patients with subarachnoid haemorrhage, aneurysm clipping was complicated by an acute episode of ischaemia in three patients. The changes in amino acid concentrations in these patients are shown in table 2 .

Of the 12 patients, cerebral ischaemia due to hypotension, intracranial hypertension, or contusions was detected in six. In these patients, characteristic patterns of changes in amino acid concentration were seen. Increased concentrations of glutamate and aspartate were accompanied by large increases in the concentration of GABA. There were less pronounced increases in the concentrations of glycine and taurine. Overall, there was a strong correlation between the concentrations of glutamate and GABA $(r=0.71 \mathrm{p}<0.005)$. The concentrations of the non-transmitter amino acids threonine and valine remained stable or showed modest increases.

\section{DISCUSSION}

We have found in this study that during basal quiescent conditions, the concentrations of amino acids tended to be stable. There were consistently higher concentrations of glutamine than the other amino acids. Overall glutamate concentrations were somewhat higher than the value accepted as "normal" for human cerebral extracellular glutamate $(2 \mu \mathrm{M}) .{ }^{12}$ During cerebral ischaemia, the concentration of glutamate and aspartate increased confirming other clinical microdialysis studies. ${ }^{11-131920}$ Direct comparisons of concentrations between studies are difficult due to variation in flow rates and membrane lengths. ${ }^{47}$ Concentrations of GABA under basal conditions were extremely low $(<0.002 \mu \mathrm{M}$ to $0.02 \mu \mathrm{M})$. However, during periods of ischaemia, there were large increases in the concentration of GABA. There was a strong correlation between the concentrations of glutamate and GABA, indicating that, in the human brain, cerebral ischaemia is associated with an increase in both excitatory and inhibitory amino acids.

It is unlikely that the change in either glutamate or GABA can be attributed to concomitant medication. Propofol is used routinely in the operating theatre and neurointensive care unit and has been shown to possess GABA agonist 

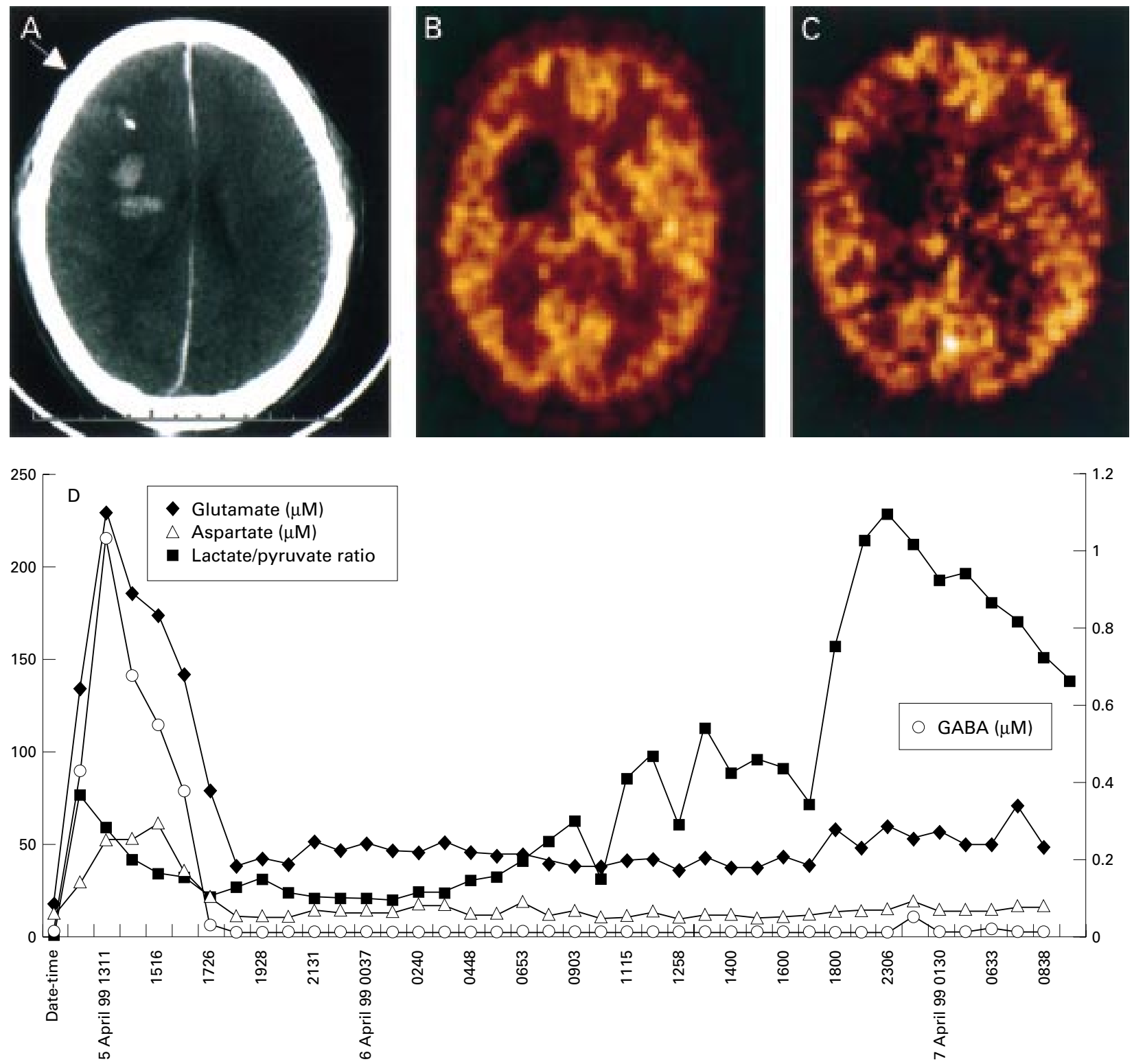

Figure 3 Severe head injury: illustrative case history 2. (A) CT showing pericontusional location of monitoring probes (arrow); (B) $\mathrm{H}_{2}{ }^{15} \mathrm{O} P E T$ showing reduced blood flow in the region of contusion (threshold from $0-60 \mathrm{ml} / 100 \mathrm{mg} / \mathrm{min}$ ); $(C){ }^{15} \mathrm{O}_{2}$ PET showing reduced oxygen metabolism in the region of contusion (threshold from $0-200 \mu \mathrm{mol} / 100 \mathrm{~g} / \mathrm{min}$ ); (D) microdialysis results showing increases in glutamate, aspartate and GABA concentrations in the region of the contusion. Note the sustained rise in the lactate/pyruvate ratio.

properties. ${ }^{48-53}$ The rate of administration of propofol remained constant during the episodes of cerebral ischaemia and the pattern of changes which we have found in these patients resemble the findings of animal models of ischaemia which were performed in the absence of propofol. ${ }^{21-34}$

The origin of increased concentrations of glutamate and other amino acids in association with acute cerebral ischaemia is unclear. Explanations include excessive release of glutamate and impaired reuptake as a consequence of neuronal damage. ${ }^{54-58}$ Microdialysis studies have reported a neuronal origin of GABA with a portion of the basal concentration derived from neurotransmission. ${ }^{59}{ }^{60}$ The increase in extracellular GABA concentrations during ischaemia may be due to excessive release resulting from membrane damage. ${ }^{37}$ However, it is possible that the GABA detected is the consequence of increased production and release of GABA in an attempt to counteract the excitatory amino acid surge as an endogenous protective mechanism. This is supported by the difference in the increase in the GABA concentrations compared to the other amino acids and evidence that GABA inhibits glutamate release via pre-synaptic receptors. ${ }^{61}$ This concurs with the data from animal studies that treatments which potentiate the action of GABA reduce neuronal injury. ${ }^{62-68}$ Further studies are, however, required to support this concept of specificity of a neuroprotective mechanism for GABA in humans, particularly to determine whether the increase in GABA is greater than that of the non-transmitter amino acids in the context of GABA, glutamate, and aspartate being the most abundant tissue amino acids.

These findings raise the possibility of a role for GABA agonists or GABA uptake inhibitors in the treatment of patients at risk from cerebral ischaemia-for example, stroke, subarachnoid haemorrhage, and head injury. ${ }^{33}{ }^{69-72}$ Chlormethiazole has been shown to possess a GABA agonist action and is currently undergoing investigation in patients with stroke. ${ }^{73}$ Propofol, also shows GABA agonist properties and our results may therefore support the use of this drug in acute cerebral ischaemia. ${ }^{48}$ However, it is becoming increasingly clear that single amino acids cannot be considered in isolation, and the importance of potential endogenous GABA neuroprotection 
Table 2 Changes in excitatory, inhibitory, and non-transmitter amino acid concentrations after an acute ischaemic insult in three patients $(A, B, C)$ during aneurysm surgery (CMA70 $10 \mathrm{~mm}$ catheter perfused with Ringer's solution at 1 $\mu l / \min )$

\begin{tabular}{|c|c|c|c|c|c|c|c|}
\hline \multirow[b]{2}{*}{$\begin{array}{l}\text { Amino acid } \\
\text { type }\end{array}$} & \multirow[b]{2}{*}{$\begin{array}{l}\text { Amino acid } \\
\text { name }\end{array}$} & \multicolumn{2}{|c|}{$\begin{array}{l}\text { Patient A } \\
\text { concentration }(\mu \mathrm{M})\end{array}$} & \multicolumn{2}{|c|}{$\begin{array}{l}\text { Patient B } \\
\text { concentration }(\mu \mathrm{M})\end{array}$} & \multicolumn{2}{|c|}{$\begin{array}{l}\text { Patient C } \\
\text { concentration }(\mu \mathrm{M}) \\
\text { illustrative case } 3\end{array}$} \\
\hline & & $\begin{array}{l}\text { Baseline } \rightarrow \\
\text { ischaemia }\end{array}$ & Ratio & $\begin{array}{l}\text { Baseline } \rightarrow \\
\text { ischaemia }\end{array}$ & Ratio & $\begin{array}{l}\text { Baseline } \rightarrow \\
\text { ischaemia }\end{array}$ & Ratio \\
\hline \multirow[t]{2}{*}{ Excitatory } & Glutamate & $18 \rightarrow 49$ & 2.7 & $7.8 \rightarrow 30$ & 3.8 & $11 \rightarrow 93$ & 8.1 \\
\hline & Aspartate & $5.4 \rightarrow 10$ & 1.9 & $9.6 \rightarrow 14$ & 1.5 & $7.8 \rightarrow 19$ & 2.5 \\
\hline \multirow[t]{3}{*}{ Inhibitory } & GABA & $0.08 \rightarrow 0.82$ & 10 & $0.14 \rightarrow 0.95$ & 6.8 & $0.01 \rightarrow 14$ & 1350 \\
\hline & Glycine & $25 \rightarrow 23$ & 0.9 & $22 \rightarrow 38$ & 1.7 & $17 \rightarrow 18$ & 1.1 \\
\hline & Taurine & $14 \rightarrow 10$ & 0.7 & $1.5 \rightarrow 6.5$ & 4.3 & $10 \rightarrow 18$ & 1.7 \\
\hline \multirow[t]{13}{*}{ Non-transmitter } & Alanine & $33 \rightarrow 31$ & 0.9 & NA & & $14 \rightarrow 22$ & 1.6 \\
\hline & Arginine & $11 \rightarrow 8.7$ & 0.8 & NA & & $9.2 \rightarrow 10$ & 1.1 \\
\hline & Asparagine & $3.5 \rightarrow 3.0$ & 0.9 & $2.8 \rightarrow 6.0$ & 2.1 & $8.4 \rightarrow 22$ & 2.6 \\
\hline & Citrulline & $2.2 \rightarrow 1.6$ & 0.7 & $1.5 \rightarrow 4.6$ & 3.1 & $1.5 \rightarrow 1.6$ & 1.0 \\
\hline & Glutamine & $171 \rightarrow 119$ & 0.7 & $87 \rightarrow 199$ & 2.3 & $151 \rightarrow 240$ & 1.6 \\
\hline & Histidine & $18 \rightarrow 12$ & 0.7 & $5.7 \rightarrow 13$ & 2.3 & $1.2 \rightarrow 0.01$ & 0.01 \\
\hline & Methionine & $2.7 \rightarrow 2.7$ & 1 & $1.8 \rightarrow 5.3$ & 2.9 & $3.9 \rightarrow 5.3$ & 1.4 \\
\hline & Phenylalanine & $8.0 \rightarrow 6.6$ & 0.8 & NA & & $7.6 \rightarrow 15$ & 2.0 \\
\hline & Serine & $14 \rightarrow 14$ & 1.0 & $32 \rightarrow 51$ & 1.6 & $17 \rightarrow 15$ & 0.9 \\
\hline & Threonine & $29 \rightarrow 40$ & 1.4 & $10 \rightarrow 25$ & 2.5 & $7.6 \rightarrow 8.2$ & 1.1 \\
\hline & Tryptophan & $2.5 \rightarrow 1.9$ & 0.8 & $4.9 \rightarrow 14$ & 2.9 & $3.4 \rightarrow 4.7$ & 1.4 \\
\hline & Tyrosine & $7.3 \rightarrow 5.9$ & 0.8 & $6.3 \rightarrow 12$ & 1.9 & $4.6 \rightarrow 5.3$ & 1.2 \\
\hline & Valine & $32 \rightarrow 29$ & 0.9 & $15 \rightarrow 44$ & 3.0 & $21 \rightarrow 24$ & 1.2 \\
\hline $\begin{array}{l}\text { The number prec } \\
\text { value during the } \\
\text { increases in GA } \\
\text { 3. Alanine, argi }\end{array}$ & $\begin{array}{l}\text { ding the arrow } \\
\text { chaemic insult. } \\
\text { A concentration } \\
\text { ne, and phenylo }\end{array}$ & $\begin{array}{l}\text { presents the b } \\
\text { ee ratio is the } \\
\text { ompared with } \\
\text { anine measure }\end{array}$ & the oth & $\begin{array}{l}\text { nino acids. Pa } \\
\text { not available }\end{array}$ & after th & $\begin{array}{l}\text { row represent } \\
\text { e the relatively } \\
\text { ustrative case } \\
\text { tient B. }\end{array}$ & $\begin{array}{l}\text { the } \\
\text { larger } \\
\text { istory }\end{array}$ \\
\hline
\end{tabular}

may help to explain the lack of efficacy of the phase III clinical trials using glutamate antagonist drugs in head injury. ${ }^{74-78}$

In conclusion, this study shows that monitoring brain extracellular neurotransmitter amino acid concentrations in patients using microdialysis is feasible and safe. Our results confirm the occurrence of increases in excitatory amino acid concentrations in patients with cerebral ischaemia and show that these increases are associated with increases in the inhibitory amino acids. These findings raise the possibility of an endogenous GABA mediated neuroprotective mechanism and a potential indication for the use of exogenous GABA agonists in the treatment of cerebral ischaemia in stroke, head injury, and subarachnoid haemorrhage. Further investigation using a combined basic experimental and clinical approach is

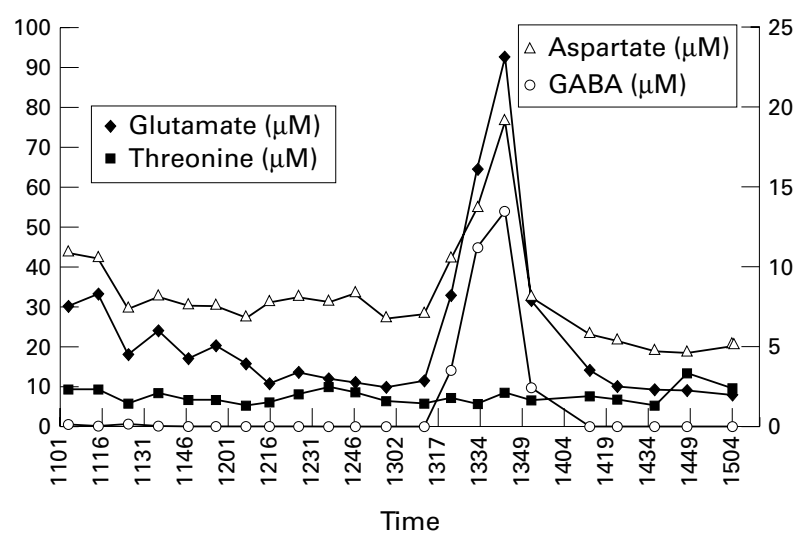

Figure 4 Subarachnoid haemorrhage aneurysm clipping: illustrative case history 3 showing the time course of change in amino acid concentrations during an acute episode of ischaemia (arrow) demonstrating reversible increases in glutamate, aspartate, and GABA. There were no significant changes in the concentration of the non-transmitter amino acids threonine and valine. required to substantiate the nature of a GABA-mediated neuroprotective action, in particular to determine specific patterns and time course of production and release into the extracellular space.

\section{ACKNOWLEDGEMENTS}

PJH is supported by a Royal College of Surgeons of England Research Fellowship, British Brain and Spine Foundation Research Fellowship,

Table 3 Mean (basal conditions) and maximum (ischaemia) values for amino acids in patients with head injury using a CMA70 microdialysis catheter 110 $\mathrm{mm}$ membrane) perfused with Ringer's solution at 0.3 $\mu \mathrm{l} / \mathrm{min}$

\begin{tabular}{lllll}
\hline $\begin{array}{l}\text { Amino acid } \\
\text { type }\end{array}$ & $\begin{array}{l}\text { Amino acid } \\
\text { name }\end{array}$ & $\begin{array}{l}\text { Basal } \\
\text { concentration } \\
\mu M\end{array}$ & SD & $\begin{array}{l}\text { Ischaemia } \\
\text { concentration } \\
\mu M\end{array}$ \\
\hline Excitatory & Glutamate & 15.5 & 7.37 & 230 \\
& Aspartate & 4.45 & 2.29 & 112 \\
Inhibitory & GABA & 0.24 & 0.36 & 35.7 \\
& Glycine & 69.9 & 26.1 & 523 \\
& Taurine & 9.0 & 12.3 & 172 \\
Non-transmitter & Alanine & 99.4 & 35.6 & 273 \\
& Arginine & 26.9 & 14.7 & 203 \\
& Asparagine & 25.5 & 6.78 & 76.9 \\
& Citrulline & 4.24 & 1.98 & 27.3 \\
& Glutamine & 1379 & 409.8 & 3955 \\
& Histidine & 65.0 & 28.9 & 163 \\
& Methionine & 19.8 & 5.43 & 170 \\
& Phenylalanine & 48.1 & 20.5 & 181 \\
& Serine & 53.9 & 20.2 & 148 \\
& Threonine & 72.9 & 15.8 & 218 \\
& Tryptophan & 9.30 & 4.43 & 77.5 \\
& Tyrosine & 29.5 & 12.1 & 100.3 \\
& Valine & 109 & 50.0 & 385 \\
\hline
\end{tabular}


and University of Cambridge Sackler award. The work of the Wolfson Brain Imaging Centre and Academic Neurosurgery in acute brain injury is supported by Foresight Technology and the Medical Research Council. We acknowledge the support of the staff of the Wolfson Brain Imaging Centre and collaboration with Professor U Ungerstedt and Professor R Bullock. We thank Dr DBA Hutchinson for supplying the cranial access device, which has patents pending and is the subject of commercial development by DBAH and the authors.

\section{Authors' affiliations}

P J Hutchinson, M T O'Connell, P G Al-Rawi, C R Kett-White, L B Maskell, J D Pickard, P J Kirkpatrick, Academic Department of Neurosurgery, University of Cambridge, Box 167, Addenbrooke's Hospital, Cambridge CB2 2QQ, UK

A K Gupta, Department of Anaesthesia

P J Hutchinson, M T O'Connell, C R Kett-White, J D Pickard, P J

Kirkpatrick, Wolfson Brain Imaging Centre

\section{REFERENCES}

1 Rothman SM, Olney JW. Excitotoxicity and the NMDA receptor. Trends Neurosci 1987;10:299-302.

2 Olney JW. Glutamate induced neuronal necrosis in the infant mouse hypothalamus. An electron microscope study. J Neuropathol Exp Neurol 1971;30:75-90

3 Rothman SM. Synaptic release of excitatory amino acid transmitter mediates anoxic neuronal death. J Neurosci 1984:4:1884-91.

4 Meldrum B, Evans M, Griffiths T, et al. Ischaemic brain damage: the role of excitatory activity and of calcium entry. $\mathrm{Br} J$ Anaesthesiol 1985:57:44-6

5 Choi DW, Maulucci-Gedde M, Kriegstein AR. Glutamate neurotoxicity in cortical cell culture. J Neurosci 1987:7:357-68.

6 Siesjo BK. Pathophysiology and treatment of focal cerebral ischaemia. Part I: Pathophysiology. J Neurosurg 1992;77: 169-84.

7 Siesjo BK. Pathophysiology and treatment of focal cerebral ischaemia. Part II: Mechanisms of damage and treatment. J Neurosurg 1992;77:337-54

8 Teasdale GM, Graham DI. Craniocerebral trauma: protection and retrieval of the neuronal population after injury. Neurosurgery 1998;43:723-38.

9 Lynch DR, Dawson TM. Secondary mechanisms in neuronal trauma. Curr Opin Neurol 1994;7:510-16.

10 Ungerstedt $U$. Microdialysis-principles and applications for studies in animals and man. J Intern Med 1991;230:365-73.

11 Persson L, Valtysson J, Enblad P, et al. Neurochemical monitoring using intracerebral microdialysis in patients with subarachnoid haemorrhage. Neurosurg 1996;84:606-16

12 Bullock R, Zauner A, Woodward JJ, et al. Factors affecting excitatory amino acid release following severe human head injury. $J$ Neurosurg 1998;89:507-18.

13 Vespa $\mathbf{P}$, Prins $M$, Ronne-Engstrom $E$, et al. Increase in extracellular glutamate caused by reduced cerebral perfusion pressure and seizures after traumatic brain injury: a microdialysis study. J Neurosurg 1998;89:971-82.

14 Robertson CS, Gopinath SP, Uzura M, et al. Metabolic changes in the brain during transient ischemia measured with microdialysis. Neurol Res 1998;20(suppl 1):S91-4

15 Bachli H, Langemann H, Mendelowitsch A, et al. Microdialytic monitoring during cerebrovascular surgery. Neurol Res 1996;18:370-6.

16 During MJ, Spencer DD. Extracellular hippocampal glutamate and spontaneous seizure in the conscious human brain. Lancet 1993;341:1607-10

17 Hutchinson PJ, Al-Rawi PG, O'Connell MT, et al. Monitoring of brain metabolism during aneurysm surgery using microdialysis and brain multiparameter sensors. Neurol Res 1999;21:352-8.

18 Persson L, Hillered L. Chemical monitoring of neurosurgical intensive care patients using intracerebral microdialysis. J Neurosurg 1992;76:72-80.

19 Mendelowitsch A, Sekhar LN, Wright DC, et al. An increase in extracellular glutamate is a sensitive method of detecting ischaemic neuronal damage during cranial base and cerebrovascular surgery. An in vivo microdialysis study. Acta Neurochir Wien 1998;140:349-55.

20 Hutchinson PJ, Al-Rawi PG, O'Connell MT, et al. On-line monitoring of substrate delivery and brain metabolism in head injury. Acta Neurochir Suppl 2001;76:431-5.

21 Benveniste H, Drejer J, Schousboe A, et al. Elevation of the extracellular concentrations of glutamate and aspartate in rat hippocampus during transient cerebral ischaemia monitored by intracerebral microdialysis. $J$ Neurochem 1984:43:1369-74.

22 Hagberg $\mathbf{H}$, Lehman A, Sandberg $M$, et al. Ischaemia-induced shift of inhibitory and excitatory amino acids from intra- to extracellular compartments. J Cereb Blood Flow Metab 1985;5:413-19.

23 Hagberg $\mathbf{H}$, Andersson P, Kjellmer I, et al. Extracellular outflow of glutamate, aspartate, GABA, and taurine in the cortex and basal ganglia of fetal lambs during hypoxia-ischaemia. Neurosci Lett 1987;78:311-17.
24 Globus MY, Busto R, Dietrich WD, et al. Effect of ischaemia on the in vivo release of striatal dopamine, glutamate, and gamma-aminobutyric acid studied by intracerebral microdialysis. J Neurochem 1988;51:1455-64.

25 Hillered L, Hallstrom A, Segersvard S, et al. Dynamics of extracellular metabolites in the striatum after middle cerebral artery occlusion in the rat monitored by intracerebral microdialysis. J Cereb Blood Flow Metab 1989;9:607-16

26 Butcher SP, Bullock R, Graham DI, et al. Correlation between amino acid release and neuropathologic outcome in rat brain following middle cerebral artery occlusion. Stroke 1990;21:1727-33.

27 Graham SH, Shiraishi K, Panter SS, et al. Changes in extracellular amino acid neurotransmitters produced by focal cerebral ischemia Neurosci Lett 1990;110:124-30

28 Torp $\mathbf{R}$, Arvin B, Le Peillet $E$, et al. Effect of ischaemia and reperfusion on the extra- and intracellular distribution of glutamate, glutamine, aspartate, and GABA in the rat hippocampus, with a note on the effect of the sodium channel blocker BW1003C87. Exp Brain Res 1993;96:365-76.

29 Nakata N, Kato H, Kogure K. Effects of repeated cerebral ischemia on extracellular amino acid concentrations measured with intracerebral microdialysis in the gerbil hippocampus. Stroke 1993:24:458-63.

30 Zhang J, Niu X. Changes of monoamines, purines and amino acids in rat striatum as measured by intercerebral microdialysis during ischemia/reperfusion. Chin Med Sci J 1994;9:225-9.

31 You ZB, Pettersson E, Herrera-Marschitz M, et al. Modulation of striatal aspartate and dynorphin B release by cholecystokinin (CCK-8) studied in vivo with microdialysis. Neuroreport 1994:5:2301-4.

32 Uchiyama-Tsuyuki Y, Araki H, Yae T, et al. Changes in the extracellular concentrations of amino acids in the rat striatum during transient focal cerebral ischemia. J Neurochem 1994;62:1074-8.

33 Baldwin HA, Williams JL, Snares M, et al. Attenuation by chlormethiazole administration of the rise in extracellular amino acids following focal ischaemia in the cerebral cortex of the rat. Br J Pharmacol 1994;1 12:188-94.

34 Matsumoto K, Lo EH, Pierce AR, et al. Secondary elevation of extracellualr neurotransmitter amino acids in the reperfusion phase following focal cerebral ischaemia. J Cereb Blood Flow Metab 1996;16:114-24.

35 Obrenovitch TP, Urenjak J. Altered glutamatergic transmission in neurological disorders: from high extracellular glutamate to excessive synaptic efficacy. Prog Neurobiol 1997:51:39-87.

36 Obrenovitch TP, Urenjak J. Is high extracellular glutamate the key to excitotoxcity in traumatic brain injury? J Neurotrauma 1997; 14:677-98.

37 Palmer AM, Marion DW, Botscheller ML, et al. Increased transmitter amino acid concentration in human ventricular CSF after brain trauma. Neuroreport 1994;6:153-6.

38 Meyerson BA, Linderoth B, Karlsson H, et al. Microdialysis in the human brain: extracellular measurements in the thalamus of parkinsonian patients. Life Sci 1990;46:301-8.

39 Wilson CL, Maidment NT, Shomer MH, et al. Comparison of seizure related amino acid release in human epileptic hippocampus versus a chronic, kainate rat model of hippocampal epilepsy. Epilepsy Res 1996;26:245-54

40 Kanthan R, Shuaib A. Clinical evaluation of extracellular amino acids in severe head trauma by intracerebral in vivo microdialysis. J Neurol Neurosurg Psychiatry 1995:59:326-7.

41 Hillered L, Persson L, Ponten U, et al. Neurometabolic monitoring of the ischaemic human brain using microdialysis. Acta Neurochir Wien 1990; 102:91-7.

42 Kanthan R, Shuaib A, Griebel R, et al. Intracerebral human microdialysis. In vivo study of an acute focal ischemic model of the human brain. Stroke 1995;26:870-3

43 Hutchinson PJ, Hutchinson DB, Barr RH, et al. A new cranial acces device for cerebral monitoring. Br J Neurosurg 2000;14:46-8.

44 Teasdale $\mathbf{G}$, Jennett B. Assessment of coma and impaired consciousness. A practical scale. Lancet 1974;ii:81-4.

45 Jennett B, Bond $M$. Assessment of outcome after severe brain damage. A practical scale. Lancet 1975;i:480-4

46 Teasdale GM, Drake CG, Hunt W, et al. A universal subarachnoid haemorrhage scale: report of a committee of the World Federation of Neurosurgical Societies. J Neurol Neurosurg Psychiatry 1988;51:1457.

47 Hutchinson PJ, O'Connell MT, Al-Rawi PG, et al. Clinical cerebral microdialysis: a methodological study. J Neurosurg 2000;93:37-43.

48 Hollrigel GS, Toth K, Soltesz I. Neuroprotection by propofol in acute mechanical injury: role of GABAergic inhibition. J Neurophysiol 1996:76:2412-22.

49 Davies PA, Hanna MC, Hales TG, et al. Insensitivity to anaesthetic agents conferred by a class of $\mathrm{GABA}(\mathrm{A})$ receptor subunit. Nature 1997;385:820-3.

50 Krasowski MD, Koltchine VV, Rick CE, et al. Propofol and other intravenous anesthetics have sites of action on the gamma-aminobutyric acid type $A$ receptor distinct from that for isoflurane. Mol Pharmacol 1998;53:530-8.

51 Orser BA, McAdam LC, Roder S, et al. General anaesthetics and their effects on $\mathrm{GABA}(\mathrm{A})$ receptor desensitization. Toxicol Lett 1998:100-1:217-24.

52 Belelli D, Pistis $M$, Peters JA, et al. The interaction of general anaesthetics and neurosteroids with $\mathrm{GABA}(\mathrm{A})$ and glycine receptors. Neurochem Int 1999;34:447-52

53 Antkowiak B. Different actions of general anesthetics on the firing patterns of neocortical neurons mediated by the GABA(A) receptor. Anesthesiology 1999;91:500-11. 
54 Westerink BH, de Vries JB. On the origin of extracellular GABA collected by brain microdialysis and assayed by a simplified on-line method. Naunyn Schmiedebergs Arch Pharmacol 1989;339:603-7.

55 Timmerman W, Zwaveling J, Westerink BH. Characterization of extracellular GABA in the substantia nigra reticulata by means of brain microdialysis. Naunyn Schmiedebergs Arch Pharmacol 1992:345:661-5

56 Massieu L, Morales-Villagran A, Tapia R. Accumulation of extracellular glutamate by inhibition of its uptake is not sufficient for inducing neuronal damage: an in vivo microdialysis study. J Neurochem 1995;64:2262-72.

57 Smith SE, Sharp T. An investigation of the origin of extracellular GABA in rat nucleus accumbens measured in vivo by microdialysis. J Neural Transm Gen Sect 1994;97:161-71.

58 Timmerman W, Westerink BH. Brain microdialysis of GABA and glutamate: what does it signify? Synapse 1997;27:242-61.

59 Bourdelais AJ, Kalivas PW. Modulation of extracellular gamma-aminobutyric acid in the ventral pallidum using in vivo microdialysis. J Neurochem 1992;58:2311-20.

60 Campbell K, Kalen P, Lundberg C, et al. Extracellular gamma-aminobutyric acid levels in the rat caudate-putamen: monitoring the neuronal and glial contribution by intracerebral microdialysis. Brain Res 1993:614:241-50.

61 Potasher SJ. Baclofen: effects on amino acid release and metabolism in slices of guinea pig cerebral cortex. J Neurochem 1979;32:103-9.

62 Saji M, Reis DJ. Delayed transneuronal death of substantia nigra neurons prevented by gamma-aminobutyric agonist. Science 1987;235:66-9.

63 Sternau LL, Lust WD, Ricci AV, et al. Role of gamma-aminobutyric acid in selective vulnerability in gerbils. Stroke 1989;20:281-7.

64 Johansen FF, Diemer NH. Enhancement of GABA neurotransmission after cerebral ischaemia in the rat reduces loss of hippocampal CA 1 pyramidal cells. Acta Neurol Scand 1991;84:1-6.

65 Shuaib A, ljaz MS, Hasan S, et al. Gamma vinyl GABA prevents hippocampal substantia nigra reticulata damage in repetitive transient forebrain ischaemia. Brain Res 1992;590:13-17.

66 Shuaib A, Mazagri R, ljaz S. GABA agonist "muscimol" is neuroprotective in repetitive transient forebrain ischaemia in gerbils. Exp Neurol 1993;123:284-8
67 Shuaib A liaz S, Miyashita $\mathrm{H}$, et al. Progressive decrease in extracellular GABA concentrations in the post-ischemic period in the striatum: a microdialysis study. Brain Res 1994;666:99-103

68 Ravindran J, Shuaib A, ljaz S, et al. High extracellular GABA levels in hippocampus - as a mechanism of neuronal protection in cerebral ischemia in adrenalectomized gerbils. Neurosci Lett 1994;176:209-11.

69 Cross AJ, Jones JA, Baldwin HA, et al. Neuroprotective activity of chlormethiazole following transient forebrain ischaemia in the gerbil. $\mathrm{Br} J$ Pharmacol 1991;104:406-11.

70 Fink-Jensen A, Suzdak PD, Swedberg MD, et al. The gamma-aminobutyric acid (GABA) uptake inhibitor, tiagabine, increases extracellular brain levels of GABA in awake rats. Eur J Pharmacol 1992;220:197-201.

71 Green AR, Misra A, Hewitt KE, et al. An investigation of the possible interaction of clomethiazole with glutamate and ion channel sites as an explanation of its neuroprotective activity. Pharmacol Toxicol 1998:83:90-4.

72 Sydserff SG, Cross AJ, West KJ, et al. The effect of chlormethiazole on neuronal damage in a model of transient focal ischaemia. Br J Pharmacol 1995;114:1631-5.

73 Wahlgren NG Ranasinha KW, Rosolacci T, et al. Clomethiazole acute stroke study (CLASS) results of a randomised, controlled trial of clomethiazole versus placebo in 1360 acute stroke patients. Stroke 1999;30:21-8

74 Bullock R. Excitatory amino acids following brain injury. J Neurosurg 1994;80:595-6.

75 Doppenberg EM, Bullock R. Clinical neuro-protection trials in severe traumatic brain injury: lessons from previous studies. J Neurotrauma 1997; 14:71-80.

76 Doppenberg EM, Choi SC, Bullock R. Clinical trials in traumatic brain injury. What can we learn from previous studies? Ann N Y Acad Sci 1997:825:305-22

77 Teasdale GM, Braakman R, Cohadon F, et al. The European Brain Injury Consortium. Nemo solus satis sapit: nobody knows enough alone. Acta Neurochir Wien 1997;139:797-803.

78 Medical Research Council. Neuroprotection in acute brain injury after trauma and stroke: from preclinical research to clinical trials. London: Medical Research Council, 1998.

\title{
NEUROLOGICAL STAMP
}

\author{
Julius Wagner-Jauregg (1857-1940)
}

W

agner-Jauregg began his medical studies at the University of Vienna in 1874. His career was rooted in the new fields of microscopy and experimental biology. He met and became a lifelong friend of Sigmund Freud.For a short time after leaving the institute he worked in the Department of Internal Medicine at the University of Vienna. He accepted a job in the psychiatric clinic. Even though he had no training in psychiatry or neurology he became greatly interested in the fields.

From 1889 to 1893 he was professor of psychiatry and neurology at the University of Graz. Here he became interested in the relation between cretinism and goitre. He proposed that the disease was due to thyroid deficiency and could be treated by the addition of small amounts of iodide to salt. In 1923 the Austrian government implemented the sale of iodised salt.

In 1883, during residency at the Vienna asylum, Wagner-Jauregg noted that a female patient who had contracted erysipelas experienced a remission of her psychoses. This aroused his interest. In 1890 Robert Koch developed tuberculin, which was considered to be a vaccine supposedly effective against tuberculosis. Wagner-Jauregg injected tuberculin into several patients whose psychotic symptoms were caused by neurosyphilis. He thought that if he gave them tuberculous fever, the fever would arrest the progress of neurosyphilis, on the grounds that the spirochaetes were heat sensitive. By 1909 he was regularly obtaining long term remission of neurosyphilis through the use of tuberculin. He abandoned the experiments because tuberculin was considered to be too toxic. Wagner-Jauregg then returned to the possibility of giving patients a fever with malaria, which unlike other infections had the advantage of being controlled with quinine.

In 1917 he proposed a new treatment for general paresis of the insane, which was then a relatively common disorder. In that year he inoculated nine patients with general paresis of the insane with tertian malaria and later reported that in six of these extensive remissions followed. For this work he received the Nobel prize for medicine or physiology in 1927. His ideas of non-specific therapies to increase the body's defences were in conflict with the "magic bullet" concept advanced by Paul Ehrlich.

Wagner-Jauregg was honoured philatelically by Austria in 1957, the 100th year of his birth (Stanley Gibbons 1289, Scott 615).

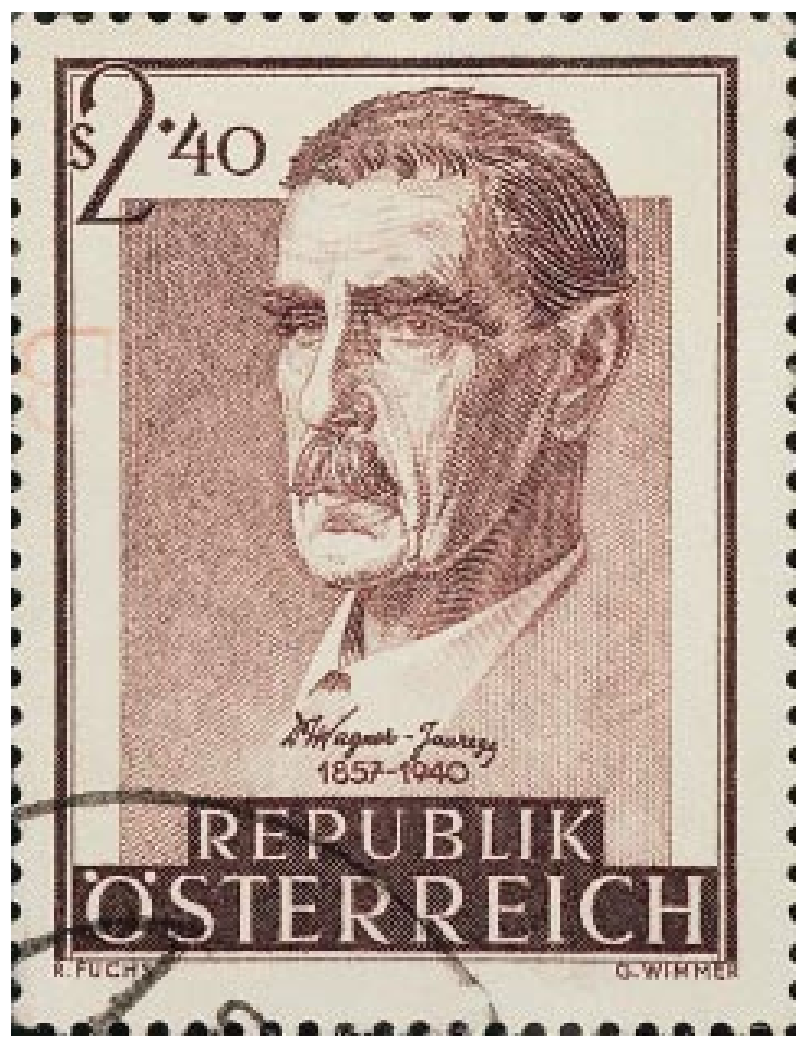

